\title{
Religiously Diverse Countries and States Have Less Inter-Religious Prejudice
}

\author{
Xuhao Zheng \\ Department of Psychology, Brigham Young University*
}

Keywords: Religion, Psychology, Contact, Conflict, Prejudice

*This manuscript was produced under the mentorship of Joshua Conrad Jackson.

Correspondence can be addressed to zhengxh98@gmail.com or

joshua.jackson@kellogg.northwestern.edu. 


\begin{abstract}
Globalization has led to an unprecedented level of religious mixing and religious diversity. These trends have led scholars to wonder whether religious diversity creates religious conflict or breeds tolerance towards different religions, but few studies have been able to draw clear conclusions. We conducted two studies to explore the relationship between religious diversity and religious prejudice. The first study collected data from 8,827 participants from 10 major religions in 37 countries around the world. We found a strong negative correlation between religious diversity and religious prejudice $(r=-.55)$ which was independent of several demographic and attitudinal covariates. The second study collected data from across the United States. We replicated the relationship between religious diversity and religious prejudice $(r=-.54)$ controlling for several group-level factors like conservatism, residential mobility, and threat. Our results suggest that contact between religious groups may be related to religious tolerance, and contrasts with "marketplace" theories of religion which suggest that religious diversity should breed competition and conflict.
\end{abstract}




\section{Religiously Diverse Countries and States Have Less Inter-Religious Prejudice}

Conflict between religious groups has been common throughout human history and continues to persist today. These religious conflicts can occur both across nations (e.g., the Crusades of the Middle Ages, or current-day hostilities between Lebanon and Israel), or within nations (the French Wars of Religion in 1562, or the Yugoslav wars of the late 20th century), and both forms of religious conflict may be rising. According to estimates from the Pew Research Center, recent years have seen more restrictions on religion, more religious hate crimes, and nearly a quarter of the world's countries experiencing a rise in religious hostilities (Pew Research Center, 2018). These trends are puzzling, and important questions remain in the study of religious conflict. Why is religious conflict more common in some areas than in others? Why could religious conflict be rising today? And what interventions could reduce religious conflict in the future?

Here we suggest that religious diversity could be a key factor in answering these questions. Religious diversity — the extent that different religions coexist within the same geographic space - has been rising over time (Smith, 2002), and it is a key factor in several past theories of religion and prejudice. One of the most popular of these theories is known as the “religious marketplace hypothesis," and was popularized in economics (Iannaccone, 1991; Stark \& Finke, 2000). According to the religious marketplace hypothesis, religions are commodities in a marketplace. Unlike race and gender, which are symbolic identities, religions are theorized to be products which can wax and wane in their influence and popularity (Finke et al., 1996; Iannaccone, 1998). Perhaps the major prediction from this model is that increased religious diversity will create a more competitive market in which religions will insist on higher levels of conviction - demonstrated through frequent prayer or service attendance - in order to maintain 
their market-share (Iannaccone, 1991, 1998). But an important consequence of increased religious conviction could be higher levels of religious prejudice. Supporting this possibility, studies have found that fundamentalist Christians are more prejudiced than their nonfundamentalist counterparts (Johnson et al., 2011, 2012; Rowatt et al., 2009), even controlling for key demographic variables, and studies of racial and ethnic prejudice have found that commitment to and pride in one's in-group is frequently associated with prejudice towards outgroups (Brewer, 1999; Jackson, Van Egmond, et al., 2019; Weisel \& Böhm, 2015). Taken together, this model suggests that religious diversity could increase religious prejudice via its effect on religious conviction.

The religious marketplace model would explain why a historical rise in globalization has co-occurred with a rise in religious hostilities such as hate-crimes and government-imposed restrictions on religious freedom. However, there may be many other reasons for this historical correlation, and factors with similar historical trends can sometimes even have a negative causal relationship. Indeed, many of the religious marketplace assumptions have now been called into question by studies showing that religious diversity is often negatively (rather than positively) correlated with religious conviction (Taylor, 2003, 2010), which suggests that religious marketplace predictions about religious diversity and inter-religious prejudice may not be borne out in data.

Moreover, a separate body of literature suggests that religious diversity have an opposite effect on prejudice. In contrast to the religious marketplace hypothesis, social psychological research on the "contact hypothesis" suggests that religious diversity could reduce prejudice between religious groups (Pettigrew, 1998). The contact hypothesis suggests that exposure to out-groups under conditions of equal status, common goals, cooperation, and institutional 
support can reduce prejudice by increasing shared understanding and humanizing out-group individuals (Allport et al., 1954; Pettigrew, 1997; Pettigrew \& Tropp, 2005). The contact hypothesis has now grown into one of the most popular theories of intergroup relations, finding support across racial, national, and ethnic groups (Christ et al., 2014; Voci \& Hewstone, 2003). Even when contact occurs virtually through computer chat or reading out-group diary entries (Jackson, Gelfand, et al., 2019), or when it is "imagined" by research participants (Crisp \& Turner, 2012), it appears to reduce self-reported prejudice, increase perceptions of inter-group similarity, and decrease people's use of negative stereotypes.

Some research has used the contact hypothesis to explore inter-religious prejudice with promising results. In one field study, Muslim Palestinian and Jewish Israeli children who were assigned to share a bunk and work together in shared activities showed reductions in prejudice (White et al., 2020). Another study using "imagined contact" found that Christians report lower anti-atheist prejudice and more trust in Atheists after imagining an interaction with an Atheist individual (LaBouff \& Ledoux, 2016). However, it is not clear whether these experiments would be consistent with real-world data where the conditions of contact theory (e.g., equal status) are not met. Indeed, analyses of prejudice across nations found that globalized countries were not necessarily more or less prejudiced, but that economic inequality moderated the relationship between globalization and prejudice such that globalized countries were less prejudiced in more equal nations but more prejudiced in less equal nations (Caluori et al., 2020). This dynamic means that religious diversity may not have any linear relationship with inter-religious prejudice across nations, or across regions within a nation.

In sum, the religious marketplace hypothesis and the contact hypothesis raise competing predictions about the relationship between religious diversity and inter-religious prejudice. 
According to the religious marketplace hypothesis, people should be more prejudiced against religious out-groups in religious diverse regions because competitive religious markets should demand greater religious conviction (Iannaccone, 1991). However, the contact hypothesis makes the opposite prediction: that religious diversity may increase positive contact between members of different religions, resulting in lower rates of inter-religious prejudice (Pettigrew \& Tropp, 2005). A third possibility is that neither model is correct, and there is no clear relationship between religious diversity and religious prejudice across regions.

\section{Current Research}

We conducted two studies to test the relationship between religious diversity and religious prejudice. Both studies tested competing hypotheses about whether religious diversity should be positively related to prejudice (religious marketplace hypothesis) or negatively related to prejudice (contact hypothesis). In Study 1, we conducted a large survey of 8688 individuals across 37 countries, which measured people's prejudice towards other religions. This allowed us to estimate the relationship between religious diversity and prejudice across a large sample of nations, and to examine whether this relationship was robust after controlling for demographic characteristics such as age, gender, socioeconomic status, and political ideology. In Study 2, we combined archival data on religious diversity and religious prejudice across U.S. states to test whether the same relationship in our international data would replicate across regions within a nation. To our knowledge, these studies are the first to use cross-cultural data to test predictions about religious diversity and religious prejudice.

\section{Study 1: Religious Diversity and Prejudice from Around the World}

\section{Method}


Participants. We collected data using an international survey of 8688 religious individuals across 37 countries. Of these participants, 8027 passed our attention checks (see "Procedure" for details) and were included in the analysis. We used the Qualtrics Panels service to recruit participants who identified with one of 10 different religions: Christianity $(N=4627)$, Islam $(N=1567)$, Hinduism $(N=437)$, Buddhism $(N=854)$, Judaism $(N=224)$, Shintoism $(N=$ 77), Sikhism $(N=10)$, Jainism $(N=27)$, Bahai $(N=1)$, and Taoism $(N=203)$.

We also used Qualtrics Panels to recruit participants who were representative of their country on the basis of age, income, education, and race. On average, our sample had a mean age of 38.11, and included 4292 participants who identified as men, 3662 participants who identified as women, 12 participants who identified as non-binary, 7 participants who identified as transgender, 13 participants who identified as intersex, 3 participants who identified as gender non-conforming, 11 participants who identified as "other," and 27 participants who preferred not to disclose their gender. Our sample was also highly racially heterogeneous, with 3411 participants who identified as white, 585 participants who identified as Black, 57 participants who identified as American Indian or Alaskan native, 573 participants who identified as Asian Indian, 601 participants who identified as Chinese, 601 participants who identified as Filipino, 214 participants who identified as Japanese, 558 participants who identified as Korean, 332 participants who identified as Vietnamese, 11 participants who identified as native Hawaiian, 9 participants who identified as Guamanian, 1 participant who identified as Samoan, 1023 participants who identified as another race, and 652 participants who preferred not to disclose their race.

\section{Measures.}


Religious Prejudice. To measure religious prejudice, we asked participants to indicate whether they were familiar with the 10 religions in our sample (described in the "participants" section). We then asked participants to rate their feelings towards each of the religions with which they were familiar using a scale from 1 ("Very cold or unfavorable feeling") to 10 ("Very warm or favorable feeling"). We computed religious prejudice by averaging the ratings for all religions except participants' own religion and then reverse-scoring the index so that a value of 10 would reflect maximal religious prejudice and a value of 1 would reflect minimal religious prejudice.

Religious Diversity. We quantified religious diversity using data from the Pew Research Center, which developed a "Religious Diversity Index" (RDI) for 232 countries across Asia and the Pacific, Europe, Latin America and the Caribbean, the Middle East and North Africa, North America, and Sub-Subharan Africa. Pew measured religious diversity using the HerfindahlHirschman Index, a popular method of quantifying concentration that has been applied to study many forms of political, organizational, or social diversity. The measure is described in depth by Pew (https://www.pewforum.org/2014/04/04/methodology-2/). The first step in creating this measure involved squaring and summing the percentages of the population from each country that belong to 8 different religious groups (Christian, Muslim, Unaffiliated, Hindu, Buddhist, Folk Religions, Other Religions, Jewish), such that higher scores reflect lower religious diversity. The second step involves inverting the scores from the first step (subtracting them from 10,000 ) so that higher scores reflect higher religious diversity, and the third step involves dividing the second-step score by 875 so that the final religious diversity index ranges from $0-10$. The least diverse countries in our sample included Morocco (0.00) and Vatican City (0.00), whereas the most diverse countries in our sample included Singapore (9.00) and Taiwan (8.20). 
Religious Conviction. To measure religious conviction, we asked participants "How would you rate the strength of your religious conviction," providing a scale from 1 ("Not religious at all") to 7 ("Highly religious").

Procedure. Participants in this study were recruited by Qualtrics Panels, which is a service which offers money - the exact monetary reward varies based on the country and the local data collection service — for people in countries around the world to take surveys. Participants signed up online for our survey through Qualtrics and were screened prior to participation so that we collected samples that were nationally representative based on age, gender, education, and socioeconomic status (SES).

After agreeing to participate in the survey, participants completed a consent form and then completed our measures of interreligious prejudice and religious conviction. Participants then provided demographic information, including age, gender, education, income (in US dollars), socioeconomic status (the MacArthur ladder; Adler et al., 1994), and political ideology (a scale ranging from 1/Very Liberal to 9/Very Conservative). The survey also included several other measures (e.g., attitudes about the relationship between religion and science) which were not relevant for the present analysis and that we did not analyze. In total, the survey was approximately 15 minutes long.

Analytic Plan. Our central research question involved testing whether religious diversity was positively or negatively associated with inter-religious prejudice across nations. We tested this research question at the country level and at the individual level. At the country level, we computed a zero-order Pearson correlation between country-level means of religious prejudice and the religious diversity index. Then at the individual level, we fit a multi-level regression with 
random intercepts in which individual-level religious prejudice was regressed on country-level religious diversity.

We next incorporated additional variables into our multilevel regression to test whether the association between religious diversity and religious prejudice was sensitive to demographic characteristics of participants (SES, age, gender, education, income, political ideology), and variation in participants' religious conviction. We were particularly interested in religious conviction because higher levels of religious conviction have been linked with religious prejudice in previous research, and the religious marketplace hypothesis suggests that religious conviction might account for a positive relationship between religious diversity and religious prejudice.

\section{Results}

What was the relationship between religious diversity and inter-religious prejudice? A nation-level correlation found a strong negative correlation, $r=-.55, p<.001$. This means that, in countries with high levels of religious diversity such as Singapore and China, people were less prejudiced against those from a different religious group. Figure 1 illustrates the nation-level correlation between religious diversity and inter-religious prejudice. 


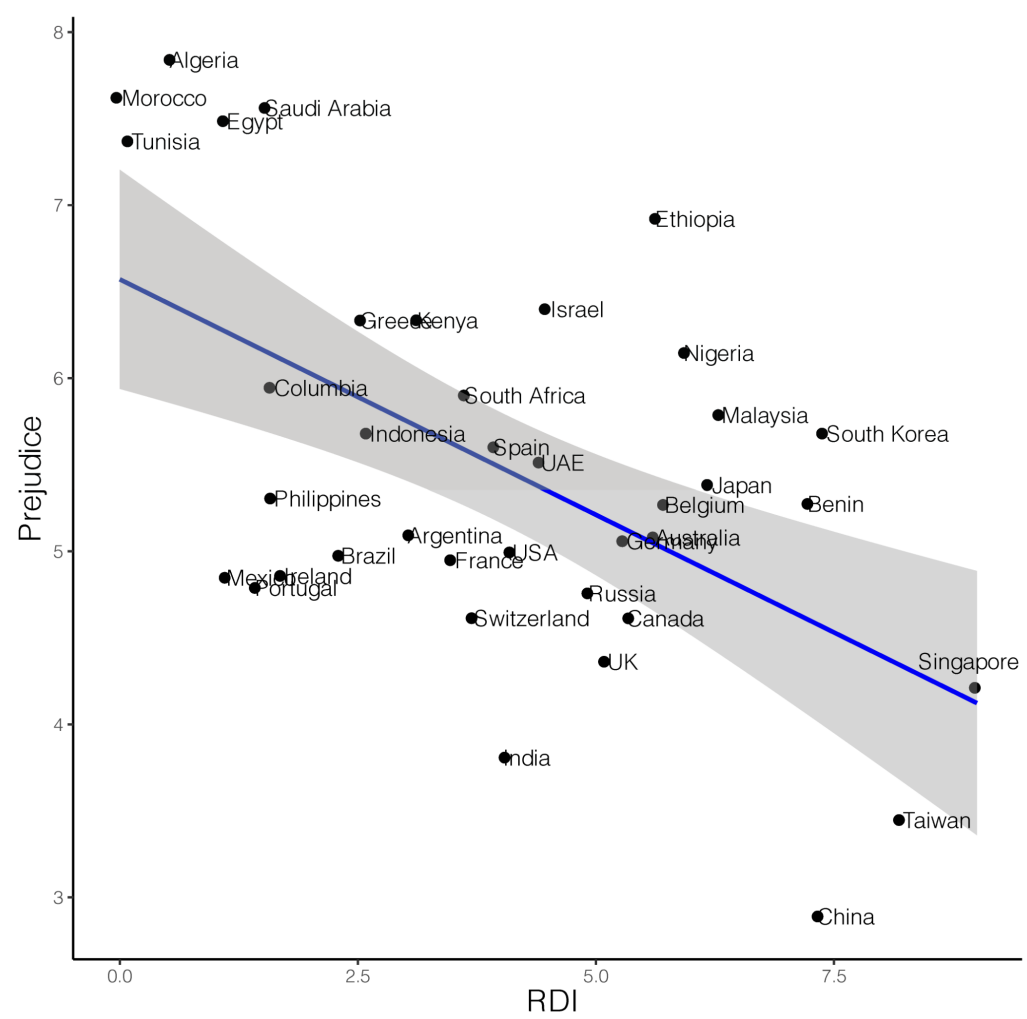

Figure 1. The nation-level relationship between religious diversity and religious prejudice. The trendline represents a regression best-fit line and the shaded region represents standard error.

We next examined the relationship between religious prejudice and religious diversity at the individual level. Multi-level regressions replicated the negative correlation that we found at the nation level, $b=-.10, S E=.04, d f=35.58, t=-2.45, p=.02$. This association replicated, and actually grew stronger, when we controlled for religious conviction, age, gender, education, income, SES, and political conservatism. In this model, we also found that younger people had more prejudice towards religious out-groups than older people, people with lower SES had more prejudice against religious out-groups than people with higher SES, more educated people had less prejudice against religious out-groups than less educated people, and relatively conservative people had more prejudice against religious out-groups than relatively liberal people. The 
statistics for these effects are all displayed in Table 1. These effects illustrate that many factors are related to religious prejudice, but more importantly for our hypothesis, they show that the relationship between religious diversity and religious prejudice is not confounded with religious conviction, or with demographic characteristics.

\section{Table 1.}

Predictors of Inter-Religious Prejudice in Study 1

\begin{tabular}{lllll}
\hline Predictor & $b(\mathrm{SE})$ & $d f$ & $t$ & $p$
\end{tabular}

Model 1

Religious diversity

$-.10$

35.58

$-2.45$

.02

Model 2

$\begin{array}{lllll}\text { Religious diversity } & -.26(.06) & 37.34 & -3.88 & <.001 \\ \text { Age } & -.01(.003) & 5687.00 & -3.25 & .001 \\ \text { Gender } & -.04(.05) & 5731.00 & -.88 & .38 \\ \text { Education } & -.18(.09) & 5734.00 & -2.06 & .04 \\ \text { Income } & -.05(.04) & 5381.00 & -1.34 & .18 \\ \text { Socioeconomic Status } & -.08(.02) & 5733.00 & -4.43 & <.001 \\ \text { Conservatism } & .06(.02) & 5740.00 & 3.62 & <.001\end{array}$

\section{Discussion}

In a worldwide survey of religious individuals, people living in religiously diverse nations showed less prejudice against out-groups than people living in religiously homogeneous nations. This provides evidence for a negative association between religious diversity and inter- 
religious prejudice. We also found that this relationship was independent of demographic variables such as age and gender and was also independent of people's level of religious conviction. Nevertheless, nations vary in many ways, and we cannot claim to have ruled out all the potential confounding variables in our study. To address this concern, we next replicated the analysis within a single nation--the United States--for a more focused test of our hypothesis.

\section{Study 2: Religious Diversity and Prejudice Across the United States}

\section{Method}

Participants. We gathered data on prejudice using the 1973-2010 waves of the General Social Survey (GSS). The GSS collects data on contemporary American society. It covers all aspects of society such as religion, civil liberties, and subjective well-being. In total, 11,577 individuals from the 50 federal states had data on our measures of interest.

\section{Measures.}

Inter-Religious Prejudice. We measured prejudice against religious out-groups using an item from the GSS in which participants indicated whether they would oppose their child marrying a Jewish person. Participants responded to this item using a scale from 1 ("Strongly Favor") to 5 ("Strongly Oppose"), meaning that higher values on this scale represented greater prejudice against an out-group religion. Judaism is a minority religion in the United States. According to PRRI, 1.5\% of Americans identify as Jewish, and our sample was made up of exclusively non-Jews. For this reason, Jackson and colleagues (2019) used opposition to one's child marrying a Jewish person as a reliable measure of prejudice against a minority religion, and we used the measure in the same way for our analysis.

Religious Diversity. To measure religious diversity, we used data from the PRRI, which computed an index where a score of "one" signifies complete diversity-every religious group is 
of equal size - while a score of "zero" indicates a complete lack of diversity, such that one religious group comprises the entire population of a given state. There was wide variation in religious diversity across states. Religiously diverse states tended to be in the Northeast, such as New Hampshire and New Jersey. Non-diverse states tended to be in the South, such as Mississippi and Arkansas.

\section{Analytic Plan.}

\section{Results}

What was the relationship between religious diversity and inter-religious prejudice? A nation-level correlation found a strong negative correlation, $r=-.54, p<.001$. This means that, in states with high levels of religious diversity such as New Hampshire and Florida, people were less prejudiced against those from a different religious group. Figure 2 illustrates the state-level correlation between religious diversity and inter-religious prejudice. We find this association particularly interesting because it was nearly identical to the association between religious diversity and prejudice at the country level, which was -.54 . 


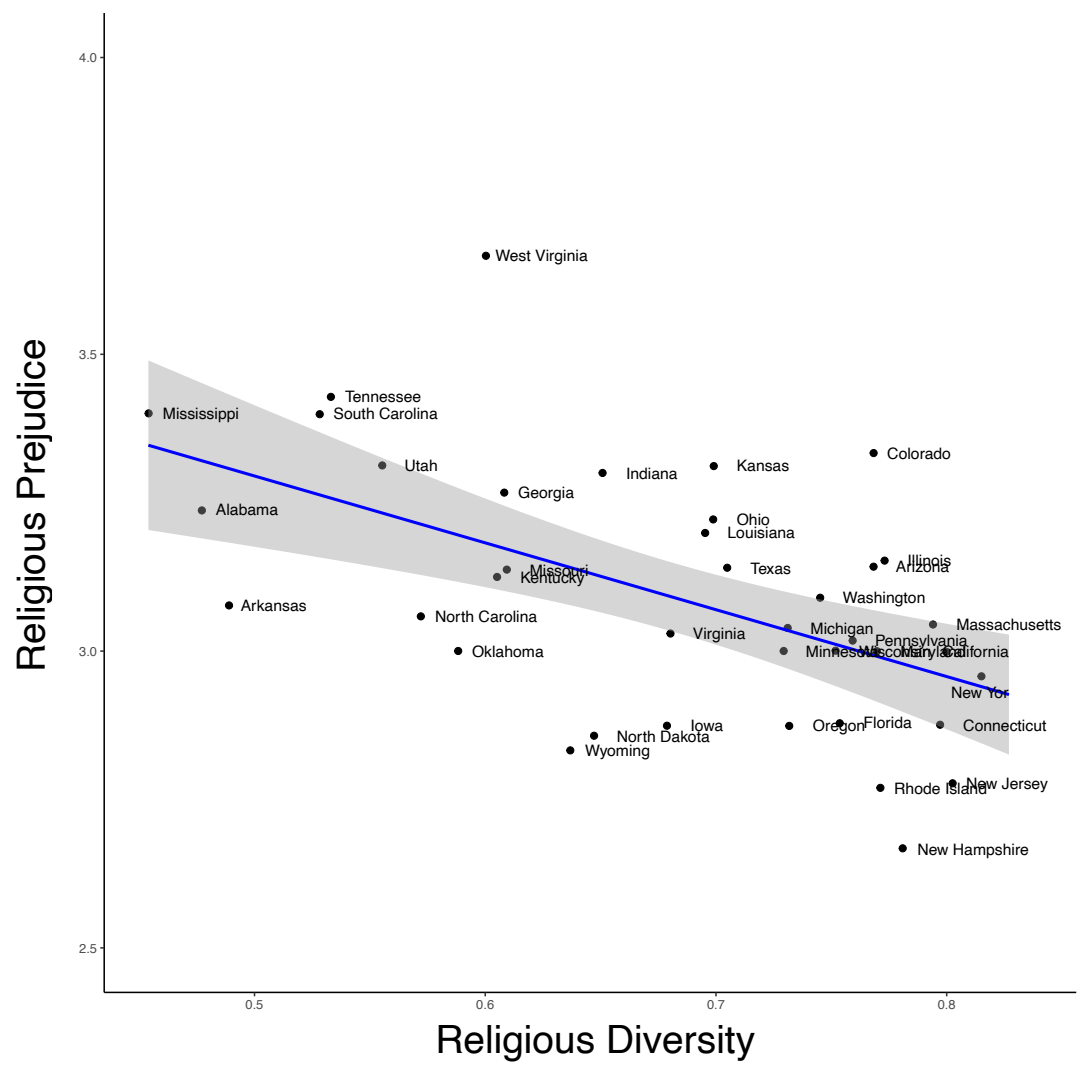

Figure 2. The state-level relationship between religious diversity and religious prejudice. The trendline represents a regression best-fit line and the shaded region represents standard error.

We next estimated the relationship between religious diversity and religious prejudice controlling for state-level covariates which could plausibly confound this relationship. We controlled for state-level conservatism, residential mobility, and ecological threat, which have each been linked to intergroup prejudice in previous research. We found that religious diversity was significant in each of these models (see Table 2), suggesting that the relationship between religious diversity and inter-religious prejudice was independent of these covariates. 


\section{Table 2.}

Predictors of Inter-Religious Prejudice in Study 2

\begin{tabular}{lllll}
\hline Predictors & $b(\mathrm{SE})$ & $d f$ & $t$ & $p$
\end{tabular}

\section{Model 1}

Religious Diversity

37

$-3.99$

$<0.001$

\section{Model 2}

Religious Diversity

$-1.00(.49)$

35

$-2.04$

0.049

Conservatism

$0.02(.06)$

35

0.264

0.79

\section{Model 3}

$\begin{array}{lllll}\text { Religious Diversity } & -1.09(.29) & 36 & -3.66 & <0.001 \\ \text { Residential Mobility } & 0.07(.21) & 36 & 0.349 & 0.729\end{array}$

\section{Model 4}

Religious Diversity

$$
-0.83(.34)
$$

35

$-2.42$

0.02

Ecological Threat

$0.05(.03)$

35

1.457

0.154

\section{Discussion}

We found a negative association between religious diversity and inter-religious prejudice across American States. Highly diverse American states had the most tolerance towards Judaism, which is a minority religion in the United States. These results replicated the country-level negative association between religious diversity and inter-religious prejudice that we documented in Study 1. We also replicated the association by investigating prejudice towards a specific minority religion (Judaism) rather than averaging across participants' favorability towards a variety of religious out-groups. 


\section{General Discussion}

The world is more religiously diverse today than at any other point in history (Kelly, 1993). Christians, Muslims, Hindus, Buddhists, and people of many other faiths will regularly mix in city streets, classrooms, and organizations. We still do not understand the full impact of this rising religious diversity, but here we explore one potential benefit. Two cross-cultural studies suggest that higher levels of religious diversity across world nations (Study 1) and American states (Study 2) are linked to lower prejudice against other religions, whether this is measured through people's attitudes towards a range of world religions (Study 1) or towards a specific minority religion (Study 2).

We note that both studies were correlational, which means we cannot claim that religious diversity causes reductions in inter-religious prejudice. However, the association was independent of several individual-level (e.g., age, gender, religious conviction, income) and group-level (residential mobility, ecological threat, political conservatism) control variables, which suggests that it was not confounded by these other factors. Moreover, our design had several features that lend us confidence in our predictions. We analyzed large samples of participants, with highly diverse backgrounds and coverage from across the globe. We also replicated our results in two different datasets, showing that the findings were consistent in a cross-national sample and across American states.

Our theories support the contact hypothesis of prejudice reduction (Pettigrew, 1997). According to the contact hypothesis, groups that are brought into contact under the right conditions will show reductions in prejudice. Our design did not allow us to check whether the ideal conditions for contact were met, but the results nevertheless suggested that diversity was linked to less prejudice between religious groups. In contrast, our results did not support 
religious marketplace theories of religious prejudice (Iannaccone, 1991), which suggest that contact between religions should increase competition between religious groups and encourage inter-religious conflict.

\section{Limitations and Future Directions}

We note that this paper has several limitations that could be addressed in future research. One limitation is that we did not conduct experiments manipulating religious diversity. Since religious diversity is a large-scale factor that characterizes nations and states, so it is difficult to manipulate at the individual level. Future studies may seek to manipulate perceptions of religious diversity. However, manipulating perceptions of religious diversity does not actually bring people from different religious backgrounds into contact, and so it may not have the same effect as actual religious diversity. Our correlational studies did measure actual religious diversity, and while we cannot claim that religious diversity causes reduced prejudice with these designs, our regressions do suggest that this link is independent of potential confounding variables like residential mobility, religious conviction, and political conservatism. If future studies attempted to manipulate religious diversity in a naturalistic or laboratory setting, we encourage them to explicitly model contact between religious groups as a potential mediator of the relationship between religious diversity and inter-religious prejudice.

A second limitation of our study is that we collected our data before the COVID-19 pandemic. COVID-19 has large-scale effects on religious beliefs (Bentzen, 2020), globalization (Sulkowski, 2020), and prejudice (Croucher et al., 2020). These dynamics may have changed the relationship between religious diversity and religious prejudice. For example, highly diverse regions may have experienced rises in religious prejudice during COVID-19. We cannot confirm

or deny this, but we encourage future research on the link between diversity and prejudice in the 
post-pandemic world. A related limitation is that our designs were cross-sectional, meaning that we could not analyze whether changes in religious diversity resulted in changes to inter-religious prejudice. A longitudinal design would allow future research to estimate this relationship with more precise causal inference.

Future studies may also seek to test moderators of our effect across different religious social identities. Past work suggests that people's religions can represent social identities just like their nationalities, racial groups, and gender groups (Cohen, 2009; Ysseldyk et al., 2010). It may be that some religious identities make believers less likely to view other religious groups favorable, even under conditions of high contact. A social identity perspective on religious prejudice may be able to address these questions and extend our research.

\section{Conclusion}

Globalization has led to an unprecedented level of religious mixing and religious diversity. Here we study how this religious diversity may relate to prejudice between different religious groups. We found a negative correlation between religious diversity and religious prejudice both worldwide (Study 1) and in American states (Study 2). In Study 1, we found that this relationship was significant controlling for education, religious conviction, age, gender, and income level. In Study 2, we showed that the relationship was robust to conservatism, residential mobility, ecological threat. We encourage future research to delve deeper into the mechanisms underlying this correlation. We also encourage future studies to explore the potential relationship between prejudice and religious diversity across cultures, and whether there might be different mediators of this relationship in different societies. With the development of globalization, we hope that this study can help in dealing with rising religious conflict. 


\section{References}

Allport, G. W., Clark, K., \& Pettigrew, T. (1954). The nature of prejudice.

Bentzen, J. (2020). In crisis, we pray: Religiosity and the COVID-19 pandemic.

Brewer, M. B. (1999). The psychology of prejudice: Ingroup love or outgroup hate? Journal of Social Issues, 55, 429-444.

Caluori, N., Brown-Iannuzzi, J. L., \& Cipolli, W. (2020). Economic Inequality Shapes the Relationship Between Globalization and Prejudice. Social Psychological and Personality Science, 1948550620960929. https://doi.org/10.1177/1948550620960929

Christ, O., Schmid, K., Lolliot, S., Swart, H., Stolle, D., Tausch, N., Al Ramiah, A., Wagner, U., Vertovec, S., \& Hewstone, M. (2014). Contextual effect of positive intergroup contact on outgroup prejudice. Proceedings of the National Academy of Sciences, 111(11), 39964000.

Cohen, A. B. (2009). Many forms of culture. American Psychologist, 64(3), 194.

Crisp, R. J., \& Turner, R. N. (2012). The imagined contact hypothesis. Advances in Experimental Social Psychology, 46, 125-182.

Croucher, S. M., Nguyen, T., \& Rahmani, D. (2020). Prejudice toward Asian Americans in the COVID-19 pandemic: The effects of social media use in the United States. Frontiers in Communication, 5, 39 .

Finke, R., Guest, A. M., \& Stark, R. (1996). Mobilizing local religious markets: Religious pluralism in the empire state, 1855 to 1865. American Sociological Review, 203-218.

Iannaccone, L. R. (1991). The consequences of religious market structure: Adam Smith and the economics of religion. Rationality and Society, 3(2), 156-177. 
Iannaccone, L. R. (1998). Introduction to the Economics of Religion. Journal of Economic Literature, 36(3), 1465-1495.

Jackson, J. C., Gelfand, M. J., Ayub, N., \& Wheeler, J. (2019). Together from afar: Introducing a diary contact technique for improving intergroup relations. Behavioral Science \& Policy, $5(1), 14-33$.

Jackson, J. C., Van Egmond, M., Choi, V. K., Ember, C. R., Halberstadt, J., Balanovic, J., Basker, I. N., Boehnke, K., Buki, N., \& Fischer, R. (2019). Ecological and cultural factors underlying the global distribution of prejudice. PLoS One, 14(9), e0221953.

Johnson, M. K., Rowatt, W. C., Barnard-Brak, L. M., Patock-Peckham, J. A., LaBouff, J. P., \& Carlisle, R. D. (2011). A mediational analysis of the role of right-wing authoritarianism and religious fundamentalism in the religiosity-prejudice link. Personality and Individual Differences, 50(6), 851-856.

Johnson, M. K., Rowatt, W. C., \& LaBouff, J. P. (2012). Religiosity and prejudice revisited: Ingroup favoritism, out-group derogation, or both? Psychology of Religion and Spirituality, $4(2), 154$.

Kelly, J. R. (1993). The religious-futures market-The Churching of America 1776-1990: Winners and Losers in Our Religious Economy by Roger Finke and Rodney Stark. Commonweal, 120(8), 27.

LaBouff, J. P., \& Ledoux, A. M. (2016). Imagining atheists: Reducing fundamental distrust in atheist intergroup attitudes. Psychology of Religion and Spirituality, 8(4), 330.

Pettigrew, T. F. (1997). Generalized intergroup contact effects on prejudice. Personality and Social Psychology Bulletin, 23(2), 173-185.

Pettigrew, T. F. (1998). Intergroup contact theory. Annual Review of Psychology, 49(1), 65-85. 
Pettigrew, T. F., \& Tropp, L. R. (2005). Allport's intergroup contact hypothesis: Its history and influence. On the Nature of Prejudice: Fifty Years after Allport, 262-277.

Rowatt, W. C., LaBouff, J., Johnson, M., Froese, P., \& Tsang, J.-A. (2009). Associations among religiousness, social attitudes, and prejudice in a national random sample of American adults. Psychology of Religion and Spirituality, 1(1), 14.

Smith, T. W. (2002). Religious diversity in America: The emergence of Muslims, Buddhists, Hindus, and others. Journal for the Scientific Study of Religion, 41(3), 577-585.

Stark, R., \& Finke, R. (2000). Acts of faith. University of California press.

Sullkowski, \Lukasz. (2020). Covid-19 pandemic; recession, virtual revolution leading to deglobalization? Journal of Intercultural Management, 12(1), 1-11.

Taylor, C. (2003). Varieties of religion today: William James revisited. Pro Ecclesia, 12(3), $375-377$.

Taylor, C. (2010). The meaning of secularism. The Hedgehog Review, 12(3), 23-35.

Voci, A., \& Hewstone, M. (2003). Intergroup contact and prejudice toward immigrants in Italy: The mediational role of anxiety and the moderational role of group salience. Group Processes \& Intergroup Relations, 6(1), 37-54.

Weisel, O., \& Böhm, R. (2015). "Ingroup love” and "outgroup hate” in intergroup conflict between natural groups. Journal of Experimental Social Psychology, 60, 110-120.

White, S., Schroeder, J., \& Risen, J. L. (2020). When “enemies” become close: Relationship formation among Palestinians and Jewish Israelis at a youth camp. Journal of Personality and Social Psychology. 
Ysseldyk, R., Matheson, K., \& Anisman, H. (2010). Religiosity as identity: Toward an understanding of religion from a social identity perspective. Personality and Social Psychology Review, 14(1), 60-71. 